\title{
Intrathecal Baclofen Therapy
}

\section{Abstract :}

Sir,

Intrathecal baclofen therapy has been used in the treatment of severe, intractable spasticity resistant to oral agents in brain and spinal cord injury since 1992. A successful trial of intrathecal baclofen infusion administered with a test dose of baclofen injection via a lumbar puncture precedes the therapy and those who respo

An intrathecal pump delivers baclofen directly into the CSF through a catheter. The pump is surgically placed under the skin of the abdomen near the waistline, under general anesthesia. It stores and releases prescribed amounts of the skin of the abdomen near the waistline, under general anesthesia. It stores and releases prescribed amounts of programmable or nonprogrammable. Using an external programmer, a physician can make adjustments in the dose, rate and timing. The reservoir can be refilled approximately every $2-3$ months by percutaneous injection. The pump is taken out and replaced at the end of the batterys life span (approximately 5-7 years). The length of time that the treatment is administered depends upon the nature of the underlying disease. For a progressive disease like multiple sclerosis, the length of time intrathecal baclofen infusion may be beneficial will be dependent upon the progression of the the length of time intrathecal baclofen infusion may be beneficial will be dependent upon the progression of the spasticity, there is no defined limit as to how long the treatment may be required and there are no firm recommendations for tolerance management. Due to limited battery life, the initial pump procedure will need to be recommendations for tolerance management. Due to limited battery life, the initial pump procedure will nefored
repeated every 5-7 years. The dosage of baclofen maybe increased due to increased tolerance of the drug.

Advantages of intrathecal baclofen infusion are direct drug administration to the CSF, reduced side effects of oral baclofen such as drowsiness or confusion, increased concentration of the drug in the CSF at higher level as compared
to the oral route. Adjustable/programmable continuous infusion makes it possible to finely titrate patients doses to the oral route. Adjustable/programmable continuous infusion makes it possible to finely titrate patients
and to vary the doses over the hours of the day. For example, the dose can be relatively low to give the patients the extensor tone needed for ambulation during the day, and increased at night, thereby improving quality of sleep. It is essential for the patient or the care giver to know the pump size, the next alarm date (which goes off to signal low pump volume), the next refill appointment which is generally a week before the alarm goes off, signs and symptoms of withdrawal and overdose of baclofen and whom to call in case of a pump problem.

A Khan

National Rehabilitation Hospital, Dun Laoghaire, Co Dublin

Email: aaisha@kemu.edu.pk

\section{References}

1. Gilmartin R, Bruce D, Storrs BB, Abbott R, Krach L, Ward J, Bloom K, Brooks WH, Johnson DL, Madsen JR, McLaughlin $\mathrm{JF}$, Nadell J. Intrathecal baclofen for management of spastic cerebral palsy: multicenter trial. J Child Neurol. $2000 ; 15: 71-77$.

2. Penn RD. Intrathecal baclofen for spasticity of spinal origin: seven years experience. J Neurosurg. $1992 ; 77: 236-240$

3. Creedon SD, Dijkers MP, Hinderer SR. Intrathecal baclofen for severe spasticity: ameta-analysis. Int J Rehabil Health 1997; 3: 171-185

4. Nance P, Schryvers O, Schmidt B. Intrathecal baclofen therapy for adults with spinal spasticity: therapeutic efficacy and effect on hospital admissions. Can J Neurol Sci 1995; 22: 22-29. 